\title{
RELEVANCIA DE LA INTEGRACIÓN SINTAGMÁTICA LINGÜÍSTICO-TEXTUAL
}

\author{
E. Ramón Trives \\ (Universidad de Murcia)
}

\begin{abstract}
RESUMEN
This paper deals with the some relevant aspects of the textual linguistic behaviour or syntagmatic integration, the TEXTUALITY, within every verbal segment obtains several stylistic and teleologic social relevance, pregnance, as component of an expressiv or communicativ configuration or Gestalt, as a necessary ectosemantic framework -in terms of Meyer Eppler - or gestaltic intergration, to be employed in the starting point of every productiv or interpretativ verbal syntagmatic or behaviour.
\end{abstract}

1. La textualidad, a nuestro juicio, objeto formal de la lingüística dinámica o textual, es el resultado de la instrumentación de la lengua en el discurso. Lo cual implica, como concausas, tanto los segmentos verbales articulados en el discurso como el hablante o usuario, en su contexto social, que entraña la puesta en funcionamiento del sintagma dialógico radical, [MUNDO-HOMBRE-LENGUA-HOMBRE-MUNDO], inherente al comportamiento verbal expresivocomunicativo, en virtud del cual el todo resultante - SENTIDO sintagmático textual- deviene superior a la suma de sus segmentos verbales componentes o partes integrantes - significados lingüístico-intuitivos-, como si de un compuesto químico se tratase. Entendemos, pues, que al proponernos como estudio el comportamiento verbal, nos situamos en la dialéctica exigida por el sintagma dialógico, en el que la lengua, con su simplicidad, debe ser utilizada adecuadamente, con todo lo que comporta el saber estar en sociedad. En tal sentido, pensamos que el conjunto de conocimientos intuitivos, reflexivos o semirreflexivos, que configuran la competencia expresivo-comunicativa de los hablantes, no se agota, en modo alguno, con el puro conocimiento lingüístico-inmanente. El estudio de éste, entendemos, se presenta y, en cierto sentido, se debe presentar al hablante con la simplicidad fonológica, morfológica y sintáctico-funcional, exigible a un instrumento, que es la lengua, apta para 
todos y al alcance de todos, los más impulsivos y los más reflexivos, los que vituperan y los que halagan, los educados y los maleducados, en su irrefrenable fuerza decidora, al margen de cualquier academicismo normativo o marchamo social, como se pone de manifiesto muy acertadamente y sin ambages en Marcial Morera (1989:29), en el ámbito concreto y fundamental de la complementación sustantiva del verbo español. Pero, por aquello del suum cuique, el puro conocimiento lingüístico-inmanente, siendo necesario e indispensable para hablar, es insuficiente para el adecuado comportamiento del hablante en sociedad, pues sólo con ese conocimiento, sin traba alguna u orientación sociopragmática, cometeríamos muchos errores sociales, disparates, insultos, etc., por muy gramaticales que fueran nuestros enunciados verbales desde la pura inocencia adánica de la mera funcionalidad sistemáticolingüística, dado que el hablante no utiliza, a la hora de hablar, puros esquemas sintácticos sólo, sino que los llena, oportuna e inoportunamente, con los inseparables monemas léxicos, que forman parte de las unidades más abundantes de la primera articulación martinetiana, unidades plenas de contenido, aunque la mayor incidencia de la economía lingüístico-instrumental afecte a las unidades morfo-sintácticas, cuya simplicidad funcional debe ser estudiada y respetada por la sedicente, no siempre con coherencia, lingüística sistemáticofuncional, como demuestra palmariamente el excelente libro de Marcial Morera. Entiendo que desde ese riguroso y necesario estudio se puede observar mejor el más complicado universo donde intervienen las normas sociales condicionadoras de las más variadas conductas sociolingüísticas.

Cuando expresamos algo o nos comunicamos verbalmente con nuestros semejantes, necesitamos dar sentido a nuestras palabras, silencios y gestos concomitantes, que no son más que virtualidades de amplia rentabilidad comunicativa, que, consecuentemente, precisan de los datos singulares procedentes del entorno en sus múltiples modalidades semánticas, físicas o prácticas, según hizo ver ya Karl Bühler. Al entrar en contacto con los diversos modos de comportamiento verbal o textos posibles, nos damos cuenta inmediatamente de que nuestra facultad perceptivo-cognitiva, cual si de una mano se tratara, va alcanzando o seleccionando las distintas palabras, grupos de palabras o equivalentes significantes, que se van plegando, como la piel al cuerpo, a las exigencias comunicativas de nuestro psiquismo intersubjetivo, y tenemos que compatibilizar lo posible y genérico, que todo instrumento comunicativo en sí mismo comporta, con lo actual y singular, que todo acto comunicativo individual exige. Nos damos cuenta de que hablar viene a ser lo mismo que significar, hacer señas, producir signos o señales, instruir a nuestros interlocutores con una serie de datos o instrucciones de forma tal que nuestros sentimientos, conceptos o vivencias puedan ser objeto de comunicación concreta_con nuestros interlocutores. 
2. Observamos que los mecanismos significantes comunicativos o meramente expresivos, siendo necesarios, desde su unitario significado lingüísticointuitivo - semántica endolingüística-, no son más que el instrumento para que la percepción de un determinado SENTIDO - ectosemántica, en términos de los teóricos de la comunicación entre seres biológicos, como Meyer Eppler- mensaje o plan conceptual o intencional previo, simultáneo o resultante, Gestalt, se produzca, como corresponde a la naturaleza simbólica del lenguaje verbal, cf. E. Trías (1994).

En consecuencia con lo anterior, aprender a hablar, aprender a utilizar con eficacia, propiedad y adecuación plena una lengua, entraña, inexorablemente, aprender a pensar, sentir, percibir u orientarnos en el mundo, con eficacia y propiedad, con la eficacia y propiedad que exige la maduración y dominio de todas las facultades humanas.

Hablar tiene por objeto orientar a nuestro interlocutor en el universo cognitivo o perceptivo dominante o ser orientado por él a través de la mano tendida intercognitiva o intersubjetiva que son las palabras, silencios, gestos, contextos y situaciones, que funcionan en el discurso como una serie de instrucciones a través de las cuales penetramos en los planteamientos perceptivos o cognitivos previos o simultáneos a cualquier expresión verbal.

Las palabras o significantes equivalentes sólo son significativas cuando se presentan como uno de los brazos —ámbito de las virtualidades- junto con el encadenamiento discursivo en función de la situación y el contexto ámbito de las actualizaciones - de la tenaza intercognitiva o interperceptiva de la comunicación verbal. Fuera de la situación intersubjetiva, las palabras no son más que puras virtualidades. Lo cual no quiere decir que las palabras fuera del discurso carezcan de sentido, como se suele afirmar. Su sentido como ya señalamos en el trabajo (1990) que sirve de base a éste- es el ya habido en la colectividad, el que ha servido a otros individuos de nuestra colectividad humana, el que de modo aproximado reflejan los diccionarios y gramáticas al uso, y cuyo conocimiento y dominio nos hace sentirnos instalados, integrados y orientados en un universo solidario, del que nos sentimos, en la medida en que nos sintamos plenamente instalados, parte integrante. A este sentido virtual to llamamos significado propiamente dicho o «significado gramatical», necesario para la existencia de una lengua.

3. Pero las palabras, más allá del contenido unitario de su significado, no adquieren sentido activo designativo-señalético alguno más que cuando son instrumentadas en una comunicación efectiva, al servicio de una planificación previa, y en función de los datos emanantes de la instrumentación intersubjetiva concreta, donde se engarzan o articulan en unidades discursivas, generadoras de sentidos novedosos o redundantes, sentidos concretos, a los que damos el nombre de sentido propiamente dicho o «significado discursivo». 
Como ya tuve ocasión de observar en otro lugar (1979: 175-177), «la lengua provee los elementos instrumentales necesarios, pero no prevé el cómo ni el cuándo del texto, lo que supondría una previa planificación en distintos textos o cierre de lo planificado en otros, de acuerdo con una intencionalidad o conciencia concomitante, que no son lengua y que nos conducen a la «ciencia del discurso», sólo instrumentalmente abordable desde la lengua o teoría de la lengua, que ha de ceder a otros ámbitos, donde cuenta no sólo la lengua, con sus paradigmas y modelos operativos, sino su rendimiento comunicativo concreto integral, o lo que es lo mismo, donde el potencial significativo lingüístico o significado cede a la concreción significativa textual o sentido, en aplicación, asimismo, del principio de economía linguuística. Los modelos textuales no están en la lengua.

4. El texto es un objetivo de la lengua en su instrumentalidad radical, pero no es un ingrediente operativo de la misma. Lingüísticamente se llega al texto, pero no se opera desde él», y, si se hace - añadimos ahora-, no es sino para llegar a otro texto, como ocurre con los distintos mecanismos metafrásticos de citas, réplicas, ampliaciones, resúmenes, etc., dentro de la correspondiente tipología textual presupuesta por el fenómeno del texto, dado que percibir o conocer viene a ser lo mismo que clasificar $o$, si se quiere, reconocer.

Las características en las que se basan los usuarios de una determinada lengua para identificar un texto, o lo que es lo mismo, para situarlo dentro de una determinada «clase de textos», pueden proceder tanto de la «configuración fono-/grafotáctica» de las unidades significantes, secuencias o microtextos convocados, como de la no menos importante «configuración semiotáctica», propia de los significados convocados por un determinado texto o discurso, generadores de isotopías configurativas perceptibles como auténtica «figura» o «Gestalt», al amparo de la actividad expresivo-comunicativa, pragmática, articulable en distintos estadios o fases - diatópica, dialéctica y dialógicaprevios al macrosignificante discursivo o instrucción-marco indispensable para su adecuado cifrado o descifrado por parte del emisor/receptor,enunciador/ enunciatario, como consecuencia del troquelado verbal, TEXTO, desde los datos procedentes del sistema verbal, los que he llamado (1979: 213), «valor inherente», objeto de la semántica lingüística, así como desde los condicionamientos emanantes del entorno socio-cultural o situación objetiva, rasgos enciclopédicos o subjetivos, en suma el llamado «valor adherente», que viene a sumarse o adherirse al significado procedente del sistema lingüístico, objeto de la semántica textual o ectosemántica anteriormente mencionada.

Ello pone de manifiesto que un texto, siguiendo a F. Rastier (1987: 9), «no es reductible a una cadena de frases». El texto se da en la medida en que el 
hablante pone en juego en el discurso «unidades de contenido» no estrictamente lingüísticas o verbales, como brillantemente hizo ver Greimas (1966: 7273) en el «marco de metodología semiótica» trazado en su Semántica Estructural. En busca de un método.

4.1. En algún sentido, en una frase como «el perro del secretario ladra», se puede manifestar tanto el clasema «animal» como el clasema «humano», «siendo únicamente un contexto más amplio el que hará decidir si se trata del perro o del secretario». Lo cual ya en 1990 me llevó a similares consideraciones a las que matizadas planteo en este lugar.

El hablante conoce o cree conocer, al proponerse instrumentar su lengua a propósito de su mundo, la solidaridad léxica planteable verbalmente entre / perro/ y /ladrar/, pero sabe, además, que cabe «animalizar» el comportamiento humano, y esto no lo sabe desde la lengua, sino desde la cultura sociosemiótica, dos sistemas semióticos convocados por igual a dinamizar el discurso a la hora de hacerlo discurrir por los cauces de las normas del comportamiento social, la cortesía, la veracidad, la persuasión, el decoro, etc.

Véase el distinto tratamiento discursivo de la relación [núcleo-sujeto/ adyacente-predicado] que presentamos en 1990, dentro de las que entendíamos y entendemos son exigencias de la lingüística dinámico-social o textual o pragmalingüística:

I: $\{$ El perro del secretario $\}>/ E 1$ secretario es un perro; es canino; es perruno/:

adyacente-predicado

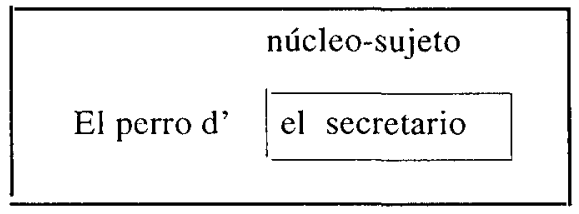

II: $\{$ EI perro del secretario $\}>/$ El secretario tiene un perro; el perro es deI secretario; es secretarial/:

adyacente-predicado

núcleo-sujeto

El perro

del secretario 
En efecto, a falta de mayor cotexto, entre el enunciado en cierto modo tautológico, centrado en [perro], y el enunciado informativo o remático, centrado en [secretario], somos proclives a preferir la interpretación que atribuye al secretario rasgos propios del perro. Lo cual nos obligaba, y obliga actualmente, a ampliar el ámbito de consideraciones semánticas, que muy oportunamente defiende S. Gutiérrez Ordóñez (1978:133-159) para los «Grupos Sintagmáticos $\mathrm{N}$ de $\mathrm{N}$, hasta incidir en lo no verbal, bien que cultural, y, consecuentemente, semiótico, pues podemos preguntarnos, al decir de Greimas (1966:72), con todo derecho «si la investigación semántica — se entiende, en mi opinión, discursivo-textual- puede o no aportar otros elementos de apreciación que permitan el reconocimiento de las continuidades isotópicas" y esto «al margen del umbral de la frase», como muy acertadamente señala Rastier (1989:10), y, precisamente, porque ese umbral existe, debemos añadir.

Greimas está hablando, en mi opinión, de una semántica textual o dinámica, la que subyace, a mi juicio, al dinamismo postulado por la linguística generativo-transformacional chomskyana originaria, la revalorizadora del dinamismo humboldtiano, más allá de las divergencias de escuela, siempre atenta a dar cuenta de las condiciones del comportamiento verbal, más allá de la esclerosis del logocentrismo autocomplaciente al margen de los hablantes y sus circunstancias.

Esa otra lingüística necesaria, la hablística o lingüística dinámica o textual, es la que puede estar en condiciones de trazar pautas de conducta o modelos predictivos del comportamiento verbal. Lo cual, a mi juicio, no puede hacerse sino transitando el puente que va del significado al sentido, de la significación a la designación, en definitiva, de la lengua al comportamiento verbal a propósito del mundo y sus hablantes, sin contaminaciones mutuas.

Al tensar el arco que va de la lengua a las condiciones de uso de la lengua por parte de los hablantes a propósito de su mundo, es cuando las unidades o segmentos verbales salen, siquiera sea momentáneamente, de sus valores unitario-intuitivos, para tornarse críticos, multivalentes, ante la urgencia de plegarse a las necesidades designativo-señaléticas, en una especie de constante forcejeo entre lo uno del sistema - que hay que describir con rigor sin injerencias designativo-extensionales, a cuyo esclarecimiento y estudio dedica sus esfuerzos el competente grupo de investigación, cuya cabeza visible es el incomparable Profesor Ramón Trujillo, con los reconocidos resultados que elogiamos desde aquí, dadas las dificultades que entraña dar cuenta de la natural y fácil instalación lingüística de los hablantes- y lo múltiple del comportamiento designativo-señalético extensional.

Y éste es a mi juicio - espero no violentar demasiado los sólidos fundamentos teóricos de su autor- el marco de lingüística dinámica que subyace a las enjundiosas reflexiones de Ignacio Bosque (1993: 9-48; 16 y ss) a la hora de 
estudiar la distinción operativa entre adjetivación relacional y calificativa, puesto que se trata de la aplicación de adjetivos, de las condiciones de su correcto uso en determinadas circunstancias de cotexto o entorno sintagmático nominal.

Cabe preguntarse si, para el comportamiento verbal o normas de uso de tales adjetivos, sigue siendo posible o conveniente el mero análisis morfológicofuncional al margen de las exigencias designativo-señaléticas pragmáticoextensionales.

Es lo que me llevó a matizar la tesis de Alarcos (1972: 85-91, 89), a propósito de los «Grupos nominales con /de/ en español», tendente a hacer ver que «el término adyacente cumple en unos y en otros ejemplos un mismo papel, el de delimitar el alcance semántico del sintagma nuclear»: lo cual es coherente dentro del marco de una lingüística sistemático-inmanente; pero al pasar a las condiciones de actualización o uso de tales tipos sintagmáticos, siquiera sea en la instantánea del empleo de determinados lexemas integrados en tales tipos sintagmáticos, debemos dar paso a la valoración lógico-discursiva, como justificación o secuela inexorable de la instrumentación verbal en un momento discursivo-textual dado, donde, sin menoscabo de la naturaleza sistemáticofuncional, sino precisamente desde ella, damos paso a otra posible y tal vez necesaria escritura recta con trazos torcidos, si se me permite el calco, donde las denominaciones de sintagma nuclear y término adyacente se aplican extensionalmente a un más allá cualitativo semio-sintáctico, pese al testigo de cargo de la mera distribución terminal morfo-sintáctica, de acuerdo con planteamientos similares a los esquemas I y II, arriba propuestos.

Lo cual me lleva a entender que planteamientos funcionales semio-sintácticos dinámico-extensionales, y no meramente morfo-sintáctico-inmanentes intensionales, son los que han llevado, no sin razón, a nuestro entender, al ilustre Académico a introducir los objetos y atributos preposicionales en el ámbito del régimen verbal, con un gesto ordenador del cajón de sastre funcional de los llamados aditamento y suplemento, sólo ordenables, desde una perspectiva dinámica lingüístico-textual integradora del estudio de las invariantes lingüísticas con el de las condiciones de uso de las variantes designativoreferenciales, dando paso a caracterizaciones lógico-designativas, donde no todo puede valer, como tuve ocasión de hacer ver al discutir la ejemplificación del muy respetado lingüista ovetense, desde una perspectiva noemática dinámico-textual al abrigo de los planteamientos dinámico-integradores de mi estimado maestro Klaus Heger (1972:5-35).

4.2. Abundando en esta lingüística dinámico-textual, en la que nos venimos instalando, piénsese en el valor delimitador de sentido de las virtualidades verbales que entraña el entorno verbal discursivo en enunciados donde un puro morfema clasificatorio como el artículo, al transponer su virtualidad clasifi- 
catoria del femenino al masculino o a la inversa, produce un sentido unívoco, que desaparece al evitar dicha transposición. Me refiero a tipos - no se olvide que estos tipos son estudiables en lingüística dinámico-textual- de enunciados como los siguientes:
1.La caballo de María es muy bruta.
1.1.El caballo de María es muy bruto.
2.La (mari)macho de María es muy dura.
2.1.El macho de María es muy duro.
3.El bala perdida del vecino no da en la diana.
3.1.La bala perdida del vecino no da en la diana.
4.El cara del picador no se sonroja nunca.
4.1.La cara del picador no se sonroja nunca.
5.El mariquita del balneario molesta mucho.
5.1.La mariquita del balneario molesta mucho.

Lo cual demuestra que los mismos segmentos morfológicos, los mismos esquemas morfosintácticos, pueden tener un sentido, significado actualizado o discursivo diverso, en función de los distintos condicionamientos semióticos, que intervienen fehacientemente en los mecanismos enuncialivo-discursivos, no ajenos a una lingüística dinámica o dinámico-textual. Traducimos e interpretamos con gratitud las muy atinadas palabras de Greimas (1970:17): «determinar las múltiples formas de la presencia del significado y los modos de su existencia, interpretarlos como componentes sintagmáticos o verticales de la significación, describir el recorrido o perfil de las transposiciones y transformaciones de los significados, son objetivos que, actualmente, no parecen ya utópicos. Sólo una semiótica de las formas podrá presentarse, en un futuro previsible, como el lenguaje para hablar del sentido, pues, justamente, la forma semiótica no es otra cosa que el sentido del sentido».

5. El comportamiento verbal, sea cual sea su complejidad, es el lugar donde las entidades verbales, de cualquier naturaleza y amplitud, convierten sus funciones suboracionales, oracionales e interoracionales en entidades programático-discursivas.

En el discurso las funciones puramente gramaticales - concordancia, adyacencia, predicación, atribución,...- pasan a eventos sometidos a valores de verdad, responsabilidad, coherencia, cortesía, oportunidad y decoro jerárquico-social, etc. Estos fenómenos convergen en la dinamica configuradora de la dialógica, en virtud de la cual el hablante elige los segmentos verbales, los distribuye y organiza en función de la fuerza persuasiva, probatoria o ficcional que logre otorgar a su discurso.

En la sintagmática lingüístico-textual las funciones gramaticales --sujeto, objeto,...-, en su reiteración o identificación en distintos esquemas sintagmático-oracionales predicativos o atributivos, dinámicos o estáticos a lo largo de 
un texto dado, se convierten en personajes, actantes o actores dotados de especiales capacidades y responsabilidades en los eventos verbalizados en un texto dado.

La sintagmática de deícticos espaciales y temporales, en su recurrencia identificativa, se convierten en el marco espacial y temporal, donde tienen lugar las características proxémicas condicionantes del desenvolvimiento de cualquier evento discursivo espacial o inespacial, temporal o intemporal.

La sintagmática, en fỉn, de significados de diversos segmentos verbales con incidencia en determinados ámbitos designativo-señaléticos convergentes, por presencia o por ausencia, de modo real o ficcional, nos aboca a la diatópica o tema programático-discursivo, que puede ser articulado dialécticamente, en función de la variada densidad epistémico-cognitiva, configuradora de un texto dado.

El hablante planifica lógico-semánticamente lo que se propone decir o hacer ver y lo modula de acuerdo con unas configuraciones o Gestalten sintagmático-cualitativas, que ofrecen el lugar utópico y límites del funcionamiento concreto de los segmentos verbales, que al acoplarse a esas exigencias programático-decidoras logran ser instrucción significante adecuada a su rentabilidad textual en función del sentido perseguido en la actividad verbal.

6. Como muestra de la variada gama de tipos sintagmático-textuales, véase el texto que analizamos seguidamente, en busca de una aproximación semiolingüística. Podemos advertir que las características morfosintácticas de los segmentos convocados por cada uno de los textos quedan abiertas a cualquier actualización de sentido concreto, pero no, obviamente, a una actualización cualquiera, en función del conjunto relacional predominante, como resultante de la inevitable intersección de las distintas unidades morfosintácticas, su coherencia y cohesión, en su caso, así como del marco configurativo o Gestalt en el que se insertan — receta, formulario, poema, carta, ...-, desde los datos contextuales y dialógico-situacionales envolventes.

\subsection{Texto.1.: FLAN DE QUESO CON SALSA DE TOMATE.}

Ingredientes:

200 gr. de queso manchego tierno.

4 huevos.

2 vasos de leche.

$100 \mathrm{gr}$. de harina.

200 gr. de nata líquida.

150 gr. de jamón serrano.

4 tomates bien maduros.

una cebolla. 
3 cucharadas de aceite.

Una pizca de nuez moscada, azúcar, sal, pimienta y orégano.

70 gr. de mantequilla o margarina.

Modo de hacerlo: Cortar la cebolla lo más finamente posible y rehogarla en el aceite a fuego suave. Cortar los tomates en trozos, retirar las pieles y las pepitas y echar los trozos en la sartén en que está la cebolla rehogada. Sazonar con sal, una pizca de azúcar y una cucharadita de orégano. Dejar hervir todo hasta obtener una salsa. Reservarla.

Fundir 50. gr. de margarina en una cazuela a fuego suave. Echar la harina y mezclar bien con la cuchara de madera. Verter la leche removiendo continuamente hasta que quede completamente incorporada. Echar entonces la nata removiendo. Echar una pizca de sal, pimienta y nuez moscada al gusto y remover nuevamente. Dejarlo un poco a fuego medio para que espese esta salsa.

Separar las yemas de la clara de los 4 huevos. Incorporar las yemas, una a una a la preparación anterior.

Rallar el queso manchego y cortar el jamón en finos trozos. Reservar unos 50 gr. de queso y echar el resto, junto con el jamón picado, a la anterior salsa y mezclar nuevamente. Batir las claras de los huevos a punto de nieve y echarlo igualmente a dicha salsa.

Untar con margarina una flanera y rellenarla con la mezcla preparadda. Cuajarla al baño de María y desmoldar sobre una bandeja cubierta con la salsa de tomate anteriormente reservada.

Espolvorear con el resto del queso manchego rallado y servir caliente. (La Mancha y el queso manchego).

\subsubsection{Desde los datos configurativos integrales, léxico-selectivos, lógico-} semánticos y organizativos, identificamos este texto con la característica clasificatoria unitaria de receta de cocina, que al mismo tiempo que lo identifica desde su especial relevancia gestáltica integral, lo distingue de otros posibles.

Este tipo de textos puede ser considerado, siguiendo a Greimas (1983:157169), como «una manifestación discursiva de una de las dimensiones de la competencia modal del individuo», la de su saber hacer, y se enmarca en una clase más amplia de discursos programadores, donde se desarrolla en forma de programación la inteligencia sintagmática, en virtud de la cual, todo texto es una instrucción o conjunto de instrucciones para alcanzar un determinado contenido textualmente configurado.

El esquema de programación de un texto de esta naturaleza puede considerarse como un ejemplo ilustrativo de lo que es la organización semióticonarrativa en general, constructo, en cuanto producción textual, y objeto esquematizable, «apto para ser definido generativamente», en frase de Greimas (o.c.), desde la perspectiva de su interpretación o reproducción.

6.1.1.1. Considerando que el comportamiento verbal hunde sus raíces, germinal o terminativamente, en la capacidad cognitiva humana $-\mathrm{F}$. Rastier (1991) y J. L. Cifuentes Honrubia (1994)—, la lectura global del Texto 1 nos 
exige ir más allá de las palabras para captar cabalmente su configuración o Gestalt integral en cuanto receta de cocina, que, obviamente, necesita de los segmentos verbales componentes, pero no se encuentra en ninguno de ellos, yendo cualitativamente más allá como constructo integral resultante. Dicha lectura nos suscita una serie de conceptos o características lógico-cognitivas fundamentales, cuyo carácter relacional semio-narrativo básico nos da la clave de su identificación clasificatoria como una receta de cocina. Se trata de parejas semio-cognitivas como las siguientes:

\begin{tabular}{|c|}
\hline 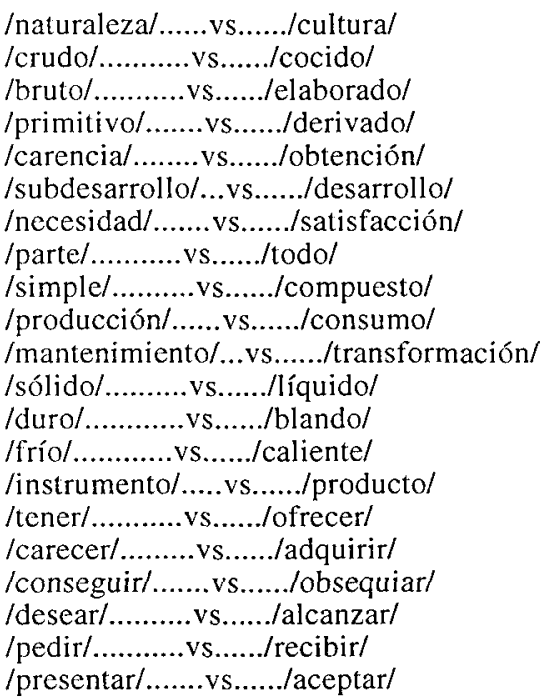 \\
\hline
\end{tabular}

Son mecanismos cognitivo-dialécticos que dinamizan y vertebran la configuración textual o Gestalt sociocultural resultante del correspondiente comportamiento verbal, de raigambre cognitiva, dado que «hablar y oír se fundan en el comprender», al decir de M. Heidegger (1974: 183). Ante un texto tenemos que reaccionar como ante una entidad integral compleja, tratando de armonizar la naturaleza dinámica configurativa resultante con la naturaleza verbal de sus segmentos integrantes. $Y$ no tanto por la inevitable tendencia humana a la evitación del vacío, horror vacui, según manifestamos en otro lugar (1994: 49), sino por razones, si se quiere epistemológicas, dado que los segmentos verbales de un texto dado son segmentos verbales textualizados, caracterizables no sólo desde su naturaleza lingüística, sino, inevitablemente, también desde su naturaleza textual, desde su evidente textualidad. En apoyo de nuestro planteamiento, podemos acudir a la teoría matemática de la integración, sin tener por qué llegar a los precisos términos de la «física matemática, donde significa suma de una serie indefinida, pero limitada, de elementos 
vinculados por un carácter común», en la clara presentación de Abraham Moles (1975: 389), y muy particularmente cuando con razón señala (ib.):

La integración es la operación que permite dar «entero» algo que al principio es una suma de partes constitutivas, ya se trate de los elementos de un mensaje, de los órganos de un sistema, de los miembros de un grupo social o de las partes de una forma (morfema).La integración es el mecanismo por el que el receptor materializa la afirmación: «El todo es mayor que la suma de sus partes».

6.1.1.2. Con esa presión o base semio-cognitiva, pasamos a caracterizar cada uno de los segmentos verbales un tanto a redromano, en la expresión unamuniana, desde la globalidad percibida en la fase de lectura previa. Así, el lexema nominal [ingredientes] adquiere, por el mero hecho de aparecer en ese texto, el valor ectosemántico adherente de denominación metadiscursiva clasemática de la sarta de sintagmas nominales subsecuente:

[200 gr. de queso manchego tierno-70 gr. de mantequilla o margarina]

todos ellos convergentes en la característica clasificatoria de PARS, [ingredientes], del TOTUM textual resultante, [flan de queso con salsa de tomate]. Se trata de parejas lógico-cognitivas que aunque no coincidan con ningún segmento verbal del texto, son los pilares fundamentales del ensamblaje argumental léxico-sintagmático de dicho texto.

6.1.1.3. Seguidamente, entramos en los programas transformativodiscursivos, como característica emanante del despliegue de los segmentos verbales en una disposición narrativo-discursiva o configuración semiosintagmática convergente en el sintagma [modo de hacerlo], que desde su modalidad programática caracteriza catafóricamente las secuencias verbales subsecuentes como transformaciones programáticas culturales.

Como puede resultar evidente, a la hora de habérnoslas con un texto dado, no estamos ante puras palabras o segmentos verbales —algo así como si las palabras de los textos sólo fueran, cual meras esencias, y no estuvieran con su comprometida existencia dentro de él-, sino ante palabras o segmentos verbales que son texto. Lo cual nos obliga a participar con la lengua en la corresponsabilidad de producir o reproducir magnitudes verbales integradas en un texto, hasta el punto - y por eso la lengua puede cambiar- de que cuando el hablante se encuentra ante situaciones textuales incómodas, no duda en modificar o enriquecer su lengua, siquiera sea en la fugaz perentoriedad de una urgencia expresivo-comunicativa. La fuerza del comportamiento textual tiene buena parte en el ir y venir de vocablos y modismos lingüísticos. Repárese, por vía de ejemplo, en la salida airosa de Sancho en el episodio de la 
bacía (cap.44, I Parte):

- Miren vuestras mercedes con qué cara podía decir este escudero que ésta es bacía, y no el yelmo que yo he dicho; y juro <...>

-En eso no hay duda - dijo a la sazón Sancho-, <...> y si no fuera por este baciyelmo no lo pasara entonces muy bien, porque hubo asaz de pedradas en aquel trance.

A propósito de lo cual, el gran lingüista y crítico literario Maurice Molho a quien desde aquí quiero dedicar mi vivo recuerdo y homenaje - supo ver este problema, al señalar, con todo acierto, entre otras razones (1976: 281-284), que «la construcción léxica baciyelmo ya es por sí sola un discurso múltiple».

6.1.1.3.1. Volviendo al texto 1, al leer el primer parágrafo bajo el marbete [Modo de hacerlo], nos encontramos con una serie de secuencias todas ellas convergentes en el espacio utópico global, donde tienen lugar las transformaciones programadas como fases programáticas integrantes de la configuración diatópica convergente o temática I, PN 1, [SALSA DE TOMATE]:

\footnotetext{
PN 1: [SALSA DE TOMATE]

Espacio utópico: [SARTÉN]

PN 11: [Cortar la cebolla]

PN 111: [Rehogarla]

PN 12: [Cortar los tomates]

PN 121: [Retirar pieles, pepitas]

PN 122: [Echar en la sartén]

PN 13: [Sazonar con...]

PN 14: [Hervir hasta obtener una salsa]

PN 141: [Reservarla]: (Espacio utópico, [BANDEJA]: parágrafo $5^{\circ}$ )
}

6.1.1.3.2. La configuración temática II, PN 2, [SALSA DE QUESO], es la integral $o$ resultante cualitativa de las instrucciones jerarquizadas textualmente reflejadas en los segmentos verbales presentes en los parágrafos segundo, tercero y cuarto:

\author{
PN 2: [SALSA DE QUESO] \\ PN 21: [Fundir margarina] \\ PN 211: [Echar harina] \\ PN 2111: [Mezclar] \\ PN 212: [Verter leche] \\ PN 2121: [Remover e incorporar] \\ PN 213: [Echar nata] \\ PN 2131: [Remover] \\ PN 2141: [Echar sal] \\ PN 2142: [Echar pimienta] \\ PN 2143: [Echar nuez moscada] \\ PN 215: [Remover] \\ PN 2151: [Dejarlo a fuego]
}

E. utópico: [CAZUELA] 
PN 221: [Separar las yemas de la clara]

PN 2211: [Incorporar las yemas]

PN 231: [Rallar el queso manchego]

PN 232: [Cortar el jamón]

PN 2311: [Reservar unos 50 gr. de queso]

PN 2312: [Echar el queso restante]

PN 2321: [Echar el jamón picado]

PN 233: [Mezclar nuevamente]

PN 2212: [Batir las claras de los huevos]

PN 22121:[Echarlo a dicha salsa]

\subsection{La configuración temática III, PN 3, [FLAN DE QUESO],} procede de la integración de las instrucciones reflejadas en el parágrafo quinto del siguiente modo:

PN 3: [FLAN DE QUESO]

PN 31: [Untar con margarina]

PN 311: [Rellenarla con la mezcla]

PN 3111: [Cuajar al baño de María]

6.1.1.3.4. La Gestalt o configuración temática IV, PN 4, [FLAN DE QUESO CON SALSA DE TOMATE] resulta de la integración de las instrucciones contenidas en los parágrafos quinto y sexto de la siguiente forma:

PN 4:[FLAN DE QUESO CON

SALSA DE TOMATE]

E.utópico: [BANDEJA]

PN 41: [Desmoldar 2 y 3 en 1]

PN 4111:[Espolvorear con el queso

rallado según 2311]

6.1.1.3.5. La configuración teleológica envolvente, PNB, [SERVIR CALIENTE] resulta de la integración máxima o cierre básico fundamental en el que convergen los diversos programas narrativos precedentes, el fin se justifica por los medios, y se refleja verbalmente en el sexto parágrafo. Se observa que el PNB, pese a su simplicidad instrumental verbal, [SERVIR CALIENTE], es un complejo programa narrativo de base, que concentra en sí un discurso múltiple, para decirlo con los ya aducidos términos de Maurice Molho. En efecto, presenta latentes funciones actanciales como el cocinero/ anfitrión, - $\mathbf{S 1 -}$, el objeto deseado, el manjar, - $\mathrm{O}-$, y el destinatariobeneficiario, $-\mathbf{S} 2-$, sin indicación verbal lexemática ni morfemática alguna, si bien el predicativo de objeto, [caliente], remite anafóricamente a la morfología flexional del núcleo nominal eludido dentro del marco relacional representado por el lexema verbal [servir].

El PNB forma el marco-fuerza ahormante o destino del objeto de cultura programado por nuestro texto, que instrumental y teleológicamente cumple con la condición de Gestalt cultural integradora de sus distintos componentes, 
materiales o verbales, instrumentados por el hombre con la mirada puesta en una determinada integración cultural, como resulta ser todo texto, aunque es particularmente evidente en una receta, donde obviamente ni los ingredientes son el manjar ni los segmentos verbales son la receta al margen de la configuración textual integradora o Gestalt que reclamamos para los productos del comportamiento verbal.

\subsubsection{El esquema programático-discursivo semio-cognitivo estructu-} ral, en el sentido dado por Lucien Tesnière (1994: 33-41) a orden estructural frente a orden lineal, nos da pie para plantear la diversa distribución o anisomorfia entre la organización semiótico-cognitiva y su verbalización mediante el despliegue lineal semiótico-articulatorio, en una cierta complicidad, en la línea de lo señalado muy certeramente por Georges Vignaux (1991:305): «les opérations langagières sont indissociables des activités cognitives hautement élaborées, celles-ci prenant appui et prétexte des premières; celles-là n'étant motivées que par la visée d'organiser et de moduler les secondes». Permítaseme presentar la Gestalt cognitivo-estructural de nuestro texto mediante el estema de la página siguiente.

7. En definitiva, cualquier texto o resultado del comportamiento verbal, cualquier expresión o comunicación, dando un sentido inclusivo a ambos térmi-nos, en orden al gradiente de menor a mayor voluntariedad o intencionalidad:

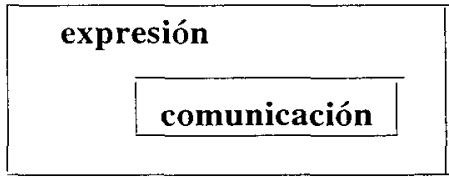

requiere el concurso de diversos interpretantes, en el sentido dado por $\mathrm{F}$. Rastier (1987) a «los distintos contextos lingüísticos o semióticos capaces de establecer una relación sémica», según distintos grados de semiotización, como se ha venido planteando en este trabajo:

configuración cognitivo-semántica

configuración tipológico-discursiva

configuración verbal expresivo-comunicativa

en virtud de lo cual cada nivel se transforma o modela en el nivel siguiente, como auténtico interpretante de relevancia sintagmático-textual, en un sentido 


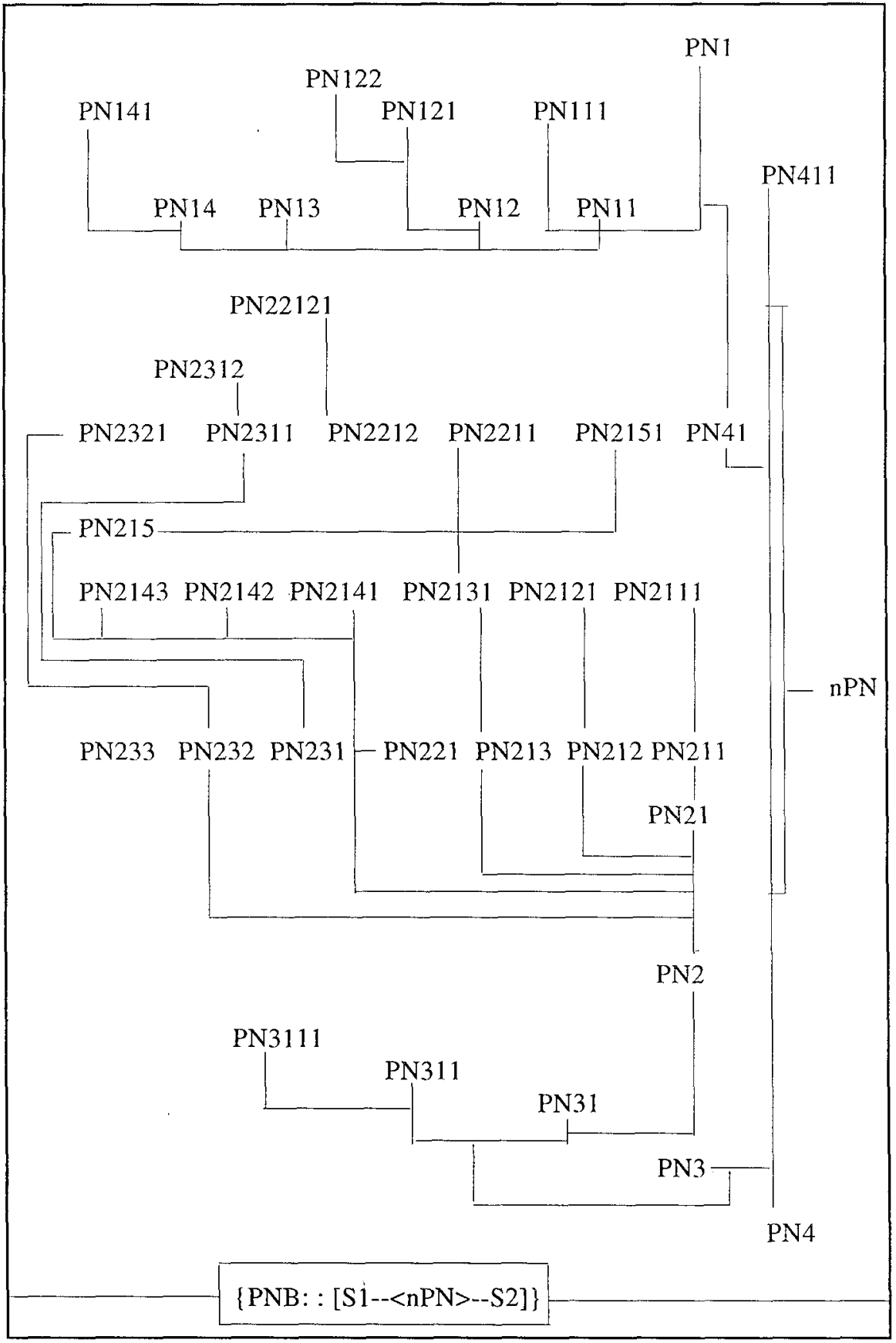


reversible, no isomórfico, de la interpretación del sentido, MUNDO, por el sonido, TEXTO, según se esté en la perspectiva enunciativa, donde la expresión verbal interpreta los contenidos cognitivo-semánticos mediante el filtro de la interpretación o configuración tipológico-discursiva; para dar paso al recorrido receptivo, no isomórfico, como se ha dicho, mediante el cual, la configuración tipológico-discursiva sirve de interpretante a la configuración semántico-cognitiva que, a su vez, filtra, condiciona o interpreta la configuración verbal sintagmático-textual, en un proceso abierto a infinitas experiencias productivo-reproductivas.

En cualquier caso, en la dialéctica planteable entre el ámbito de la lengua, en sentido saussureano, y el del texto, como resultado del comportamiento verbal, quiero manifestar, como conclusión, que el estudio del comportamiento verbal puede obtener resultados ventajosos de la convergencia o armonización del panorama ofrecido por las diversas metodologías, dado que, sin contaminaciones mutuas, todas son acaso necesarias, siendo evidente que ninguna es suficiente, pues nihil est in lingua quod non prius fuerit in oratione, como con indudable acierto señaló el incomparable Benveniste (1966:131).

\section{Referencias bibliográficas:}

ALARCOS, E. (1972): «Grupos nominales con /de/ en español», en Studia Hispanica in honorem R. Lapesa, I, Gredos, Madrid.

BENVENISTE, E. (1966): Problèmes de linguistique générale, Gallimard, 1966.

BOSQUE, I. (1993): «Sobre las diferencias entre los adjetivos relacionales y los calificativos», en Revista Argentina de Lingüística, 9(1-2), págs. 9-48

BÜHLER, K. (1961): Teoría del lenguaje, Revista de Occidente, $2^{\mathrm{a}}$.ed, Madrid. CIFUENTES HONRUBIA, J. L. (1994): Gramática cognitiva. Fundamentos críticos, Eudema, Madrid.

GARCÍA DEL CERRO, C. Y ALONSO MADERO, F. J. (1986): La Mancha y el queso manchego, Artes gráficas Antona, Tarancón.

GREIMAS, A. J. (1966): Sémantique structurale. Recherche de Méthode, Paris, Larousse.

GREIMAS, A. J. (1970): Du Sens. Essais sémiotiques, Seuil, Paris.

GREIMAS, A. J. (1983): Du Sens II, Seuil, Paris.

GUTIÉRREZ ORDÓÑEZ, S. (1978): «Grupos sintagmáticos N de N: Sintaxis y Semántica», en Estudios ofrecidos a E. Alarcos Llorach, Universidad de Oviedo, Oviedo.

HEGER, K. (1976): Monem, Wort, Satz und Text, Niemeyer, $2^{a}$.ed, Tübingen. HEIDEGGER, M. (1947): El Ser y el Tiempo, tr.de J.Gaos, Fondo de Cultura

Económica. 
MORERA, M. (1989): Sintaxis lingüistica vs. sintaxis lógica, SantaCruz de Tenerife.

MOLES, A. (1975): La comunicación y los mass media, bajo la dirección de, (versión de J. J.Ferrero), Mensajero, Bilbao, 1975.

MOLHO, M. (1976): Cervantes: raíces folklóricas, Gredos, Madrid.

RAMÓN TRIVES, E. (1972): «En torno a los conceptos de transitividad, complementación y circunstancia desde la teoría actancial y casual: problemas hispánicos», en Anales de la Universidad de Murcia, XXX, 3-4, 1972, págs. 5-35.

RAMÓN TRIVES, E. (1979): Aspectos de semántica lingüístico-textual, Istmo-Alcalá, Madrid.

RAMÓN TRIVES, E. (1990): «Aproximación semio-lingüística a los textos verbales en el marco metodológico de A. J. Greimas», en Cursos A.C.D., Albacete.

RAMÓN TRIVES, E. (1995): «Aspectos integrales de la lengua y su aplicación didáctica», en Aspectos de didáctica de la lengua y la literatura (1), Universidad de Murcia, Murcia, págs. 43-56.

RASTIER, F. (1987): Sémantique interprétative, P.U.F., Paris.

RASTIER, F. (1989): Sens et textualité, Hachette, Paris.

RASTIER, F. (1991): Sémantique et recherches cognitives, P.U.F.,Paris.

TRÍAS, E. (1994): La edad del espíritu, Destino, Madrid.

TESNIÈRE, L. (1994): Elementos de sintaxis estructural, I y II, Gredos, Madrid.

VIGNAUX, G. (1991): «Catégorisation et schématisation. Des arguments au discours», en Sémantique et cognition. Catégories, prototypes, typicalité (sous la direction de Danièle Dubois), CNRS, Paris, págs. 295-318. 